\title{
The melatonin receptor CAND2 is involved in the regulation of photosynthesis and chloroplast gene expression in Arabidopsis thaliana under photooxidative stress
}

\author{
I.A. BYCHKOV (iD), N.V. KUDRYAKOVA (iD), E.S. POJIDAEVA (iD, and V.V. KUSNETSOV ${ }^{+}$
}

K.A. Timiryazev Institute of Plant Physiology RAS, 35 Botanicheskaya St., 127276 Moscow, Russia

\begin{abstract}
Melatonin is a well-known bioactive molecule able to mitigate photooxidative damage caused by excess light. Here we have shown that mutant Arabidopsis lines with disrupted genes for melatonin putative receptor CAND2/PMTR1 and GPA1 encoding the $\alpha$-subunit of heterotrimeric G-protein were partially insensitive to melatonin treatment under high light stress. They exhibited a higher degree of photodamage due to a significantly decreased photosynthetic activity and diminished expression of chloroplast and nuclear-encoded genes and the corresponding proteins. A possible mechanism for melatonin-dependent regulation of chloroplast genes is associated with a change in the activity of the genes for chloroplast RNA polymerases. We conclude that under high light stress, melatonin may act as a hormonelike signaling molecule via the CAND2/PMTR1-mediated signaling pathway.
\end{abstract}

Keywords: chloroplast genome expression; light stress; photosynthetic activity; phytomelatonin receptor.

\section{Introduction}

Melatonin (N-acetyl-5-methoxytryptamine), an important bioactive molecule with regulatory and antioxidant functions, was first discovered in plants in 1995 (Reiter et al. 2015, Sharif et al. 2018, Sun et al. 2021). As a universal regulator, melatonin participates in a variety of processes including plant growth and development, root morphology and floral transition, leaf senescence, and fruit ripening (Sun et al. 2021). According to transcriptomic studies, melatonin, in both small and high doses, regulates the expression of a large number of genes associated with stress response, antioxidant functions, intracellular signaling mechanisms, and hormonal regulation (Weeda et al. 2014, Wan et al. 2018).

Melatonin is also involved in photosynthesis, especially when plants are challenged with abiotic stresses. In particular, melatonin treatment reduced the inhibitory effect of osmotic stress in soybean and increased PSI and PSII-related gene expression (Zhang et al. 2019). In tomato seedlings, melatonin increased PSII activity and photochemical quenching coefficient and facilitated

\section{Highlights}

- Melatonin (MT) may act via the CAND2/PMTR1 signaling pathway under high light stress

- CAND2 participates in the regulation of photosynthesis and chloroplast gene expression

- The protective antioxidant function of exogenous MT did not depend on the CAND2 pathway
Received 21 September 2021

Accepted 29 November 2021

Published online 14 December 2021

Corresponding author

phone: +74996785400

fax: +7 4996785420

e-mail: vkusnetsov2001@mail.ru

\footnotetext{
Abbreviations: $\mathrm{F}_{\mathrm{v}} / \mathrm{F}_{\mathrm{m}}$ - maximum quantum yield of PSII; HL - high light; $\mathrm{MS}$ - Murashige and Skoog medium; NEP - single-subunit nuclear-encoded RNA polymerase of the phage-type; NPQ - nonphotochemical quenching; PAM - pulse amplitude modulation; PEP - bacterial type plastid-encoded RNA polymerase; RT-qPCR - quantitative Real-Time PCR; WT - wild type; $\Phi_{\text {PSII }}$ - effective quantum yield of PSII.

Acknowledgments: This work was supported by the Russian Foundation for Basic Research project No. 19-34-90029 and partially by the state assignment of the Ministry of Science and Higher Education of the Russian Federation (No. 121040800153-1). We are grateful to Dr. Iwona Adamska for kindly supplying antibodies against ELIP1.

Conflict of interest: The authors declare that they have no conflict of interest.
} 
the repair of PSII by maintaining the availability of D1 protein, otherwise reduced by salinity stress (Zhou et al. 2016). Exogenous melatonin also improved maize photosynthetic capacity and alleviated damage caused by salinity stress (Wang et al. 2021a). A snat knockout mutant of Arabidopsis thaliana with the decreased endogenous melatonin content accumulated much less starch than the wild type and exhibited lower LHCB1, LHCB4, and RbcL protein contents suggesting the involvement of this regulator in chloroplast protein quality control (Lee and Back 2021). Melatonin is synthesized from tryptophan through several intermediates including serotonin. At the last stage, three enzymes are involved in the synthesis - serotonin $N$-acetyltransferase (SNAT), $\mathrm{N}$-acetylserotonin methyltransferase (ASMT), and caffeic acid $O$-methyltransferase (COMT) (Back et al. 2016). Knock-outs for any of the genes encoding these proteins have reduced vital indexes and increased susceptibility to stressors.

The original function of melatonin, as a direct free radical scavenger, suggests its location close to the sites of ROS formation which is essential for antioxidant activity. However, to expand its functional repertoire, it was necessary to evolve specific binding sites/receptors and associated signaling transduction (Zhao et al. 2019). In animal cells, many of the known activities of melatonin are mediated by membrane G-protein coupled receptors. In 2018, the first potential phytomelatonin receptor CAND2/PMTR1 (Candidate G-protein Coupled Receptor 2) was discovered (Wei et al. 2018). The membrane-bound receptor was shown to be involved in the stomatal closure through the $\alpha$-subunit of heterotrimeric G-protein GPA1 regulated by $\mathrm{H}_{2} \mathrm{O}_{2}$ and $\mathrm{Ca}^{2+}$ signaling molecules. The pmtrl mutants lost diurnal stomatal closure, with stomata remaining open during daytime and night, and exhibited more water loss and drought sensitivity when compared with the wild type plants ( $\mathrm{Li}$ et al. 2020). The receptor was also shown to play a key role in the melatonin-mediated plant response to osmotic stress. However, these observations were challenged by Lee and Back (2020) who argued that CAND2 is neither a phytomelatonin receptor localized in the plasma membrane nor is it involved in the melatonin-mediated defense signaling pathway via $\mathrm{G}$ protein components. Nevertheless, they did not rule out that CAND2 may be a melatonin-binding protein and that this binding may result in a decrease of free melatonin contents in plants.

Melatonin is closely associated with high-light (HL) stress tolerance in plants. Protecting the photosynthetic apparatus from photodamage is critical for plant survival since it induces the production of reactive oxygen species (ROS) (Gruszecki 2010). SNAT1 overexpressing plants exhibited increased tolerance to HL stress (Lee and Back 2018). At the same time, in snat1 mutant highly susceptible to HL stress, melatonin treatment reduced superoxide production and increased the expression of various ROSresponsive genes.

All the essential processes of photosynthesis are carried out in chloroplasts which are the main targets of HL stress.
Chloroplasts contain their genome including about 100 genes, some of which encode proteins directly involved in photosynthesis (Kusnetsov 2018). Transcription of chloroplast genes is carried out by two types of RNA polymerases: bacterial type chloroplast-encoded RNA polymerase (PEP), consisting of four subunits $\left(\alpha, \beta, \beta^{\prime}, \beta^{\prime \prime}\right)$ and a single-subunit nuclear-encoded RNA polymerase of the phage-type (NEP). The latter is represented by two enzymes: RPOTp which is targeted into chloroplasts and RPOTmp which occurs only in dicots and is imported both into chloroplasts and mitochondria (Pfannschmidt et al. 2015).

In previous work, we showed that exogenous melatonin increases the expression of the genes encoding chloroplast transcription machinery under mild photooxidative stress in Arabidopsis detached leaves (Bychkov et al. 2019). This work is aimed to elucidate whether exogenous melatonin regulates chloroplast gene expression and photosynthesis in young intact Arabidopsis plants under severe HL stress and to unravel how melatonin deficiency and disruption of its putative signaling pathway affect molecular processes in chloroplasts.

\section{Materials and methods}

Growth conditions and experimental design: Arabidopsis thaliana plants, ecotype Columbia-0, and insertion knockout mutant lines asmt (NASC680911), cand2 (NASC678658), and gpal (NASC6534) were used in the experiments. Molecular characterization of the mutants is presented in supplementary data (Fig. 1S, supplement).

The seeds were planted in Petri dishes on half-strength Murashige and Skoog (MS) medium with 1\% sucrose and $0.5 \%$ agar. After stratification for $48 \mathrm{~h}$ at $4^{\circ} \mathrm{C}$ in the dark, they were grown in a growth chamber at $23^{\circ} \mathrm{C}$ with at a $16-\mathrm{h}$ photoperiod, and PPFD of $60 \mu \mathrm{mol} \mathrm{m} \mathrm{m}^{-2} \mathrm{~s}^{-1}$. At the age of two weeks, the seedlings were transferred for $72 \mathrm{~h}$ to paper filters moistened with a liquid MS medium supplemented with $50 \mu \mathrm{M}$ of melatonin or an equal aliquot of solvent. The optimal concentration of melatonin was determined in preliminary experiments. After that, the plants were exposed to HL stress [600 $\mu \mathrm{mol}$ (photon) $\mathrm{m}^{-2} \mathrm{~s}^{-1}$ ] for $24 \mathrm{~h}$ or kept under $60 \mu \mathrm{mol}$ (photon) $\mathrm{m}^{-2} \mathrm{~s}^{-1}$ (control). At the end of the exposure, measurements were directly taken, or the samples were frozen in liquid nitrogen and stored at $-80^{\circ} \mathrm{C}$.

Pigment content and fluorimetry: Chlorophyll (Chl) and carotenoids were extracted and determined as described by Lichtenthaler (1987). Chl $a$ fluorescence parameters [the maximum quantum yield $\left(\mathrm{F}_{\mathrm{v}} / \mathrm{F}_{\mathrm{m}}\right)$, the effective quantum yield of PSII $\left(\Phi_{\mathrm{PSII}}\right)$, and nonphotochemical quenching (NPQ)] were measured using a DUAL-PAM100 (Walz, Germany) following Kozuleva et al. (2017). The following parameters were determined: measuring light $-460 \mathrm{~nm}, 9 \mu \mathrm{mol}$ (photon) $\mathrm{m}^{-2} \mathrm{~s}^{-1}$; saturating pulses $500 \mathrm{~ms}, 635 \mathrm{~nm}, 4,000 \mu \mathrm{mol}$ (photon) $\mathrm{m}^{-2} \mathrm{~s}^{-1}$; actinic light $635 \mathrm{~nm}, 37 \mu \mathrm{mol}$ (photon) $\mathrm{m}^{-2} \mathrm{~s}^{-1}$. The dark incubation time for measurements was $10 \mathrm{~min}$. 
RNA isolation and quantitative Real-Time (RT-qPCR):

Relative transcript levels of nuclear and chloroplast genes were evaluated using RT-qPCR according to Danilova et al. (2018) in a LightCycler 96 (Roche, Switzerland). The following standard thermal profile was used for all PCR reactions: $95^{\circ} \mathrm{C}$ for $5 \mathrm{~min}, 40$ cycles of $95^{\circ} \mathrm{C}$ for $15 \mathrm{~s}$, $58^{\circ} \mathrm{C} 15 \mathrm{~s}$, and $72^{\circ} \mathrm{C}$ for $25 \mathrm{~s}$. The nucleotide sequences of primers for RT-qPCR analysis are presented in Table 1S (supplement). All data were normalized to the amount of the transcript levels of the nuclear-encoded polyubiquitin $U B Q 10$ gene which was used as the internal control.

Protein isolation and Western blot analysis: Protein extraction and Western blot analysis were performed according to our previous study (Bychkov et al. 2019). In brief, the samples were blotted to PVDF membrane after SDS-PAGE electrophoresis and blots were incubated with anti-ELIP1 (Heddad et al. 2006), anti-PsbD (PSII; AS06 146), anti-RbcL (Rubisco; AS03 037), anti-AtpB (ATP synthase; AS05 085), and anti-PsaB (PSI; AS10 695) primary antibodies (Agrisera, Sweden) overnight at $4^{\circ} \mathrm{C}$ followed by the secondary antibody (anti-rabbit IgG horseradish peroxidases conjugated from Agrisera, AS09 602) for $1 \mathrm{~h}$ at room temperature according to the manufacturer's instructions. Signals from immunoblotting were detected using the ECL method (ECL Western blotting detection Kit, Bio-Rad) by the Invitrogen iBright Imaging Systems (Thermo Fisher Scientific, USA).

Endogenous melatonin (ELISA): Melatonin measurement was performed as described by Lee and Back (2018). Leaves $(0.2 \mathrm{~g})$ were ground in $2 \mathrm{ml}$ of $100 \%$ chloroform. After centrifugation for $15 \mathrm{~min}$ at $12,000 \times \mathrm{g}$, the supernatant was transferred into new tubes and placed in a vacuum evaporator until the liquid was completely removed. The precipitate was then dissolved in distilled water and vortexed for $3 \mathrm{~h}$. To determine the melatonin content, ELISA Kit CEA908GE (Cloud-Clone Corp., USA) was applied according to the manufacturer's instructions. Optical measurement was performed at $450 \mathrm{~nm}$ using a Multiskan MS Microplate Reader LabSystems 352 (Thermo/LabSystems, USA).
Statistical data processing: All experiments were performed in three biological replicates. The data were analyzed by the online calculator (https://astatsa.com/ OneWay_Anova_with_TukeyHSD/) using a one-way analysis of variance (ANOVA) followed by Tukey's method. All data are presented as means \pm their standard errors (SE).

\section{Results}

Antioxidant function, melatonin content, and genes for melatonin synthesis and signaling: HL induced oxidative damage which was manifested in an increase of lipid peroxidation, electrolyte leakage, and hydrogen peroxide contents in all genotypes (Table 2S, supplement). In parallel, protective mechanisms were reinforced as evidenced by elevated proline accumulation and SOD activity. Melatonin treatment reduced the rates of oxidative damage in the wild type and asmt but had a slightly lesser effect in cand2 and gpal.

Exogenously applied melatonin changed its endogenous concentration (Fig. 1). In the wild type, under normal light conditions, treatment with melatonin increased the endogenous content by more than 1.5 -fold. HL stress caused a twofold decrease in the content by the end of the experiment in plants without any treatment. However, there was almost no decrease in melatonin contents in treated plants under HL, as compared to treated plants under moderate light. The results were similar for the asmt mutant, which showed a reduced melatonin content and a corresponding decrease under HL. In contrast, HL promoted a greater decrease of melatonin concentration in cand2 and gpal mutants supplemented with the exogenous regulator under HL, although initial contents were comparable to those of the wild type.

The decrease in melatonin content under HL was accompanied by downregulation in the expression of genes for melatonin synthesis (SNAT1, ASMT, COMT) in the wild type plants (Table 1). Under normal conditions, the addition of exogenous melatonin slightly reduced the expression of these genes. On the other hand, during stress, melatonin increased their expression to almost

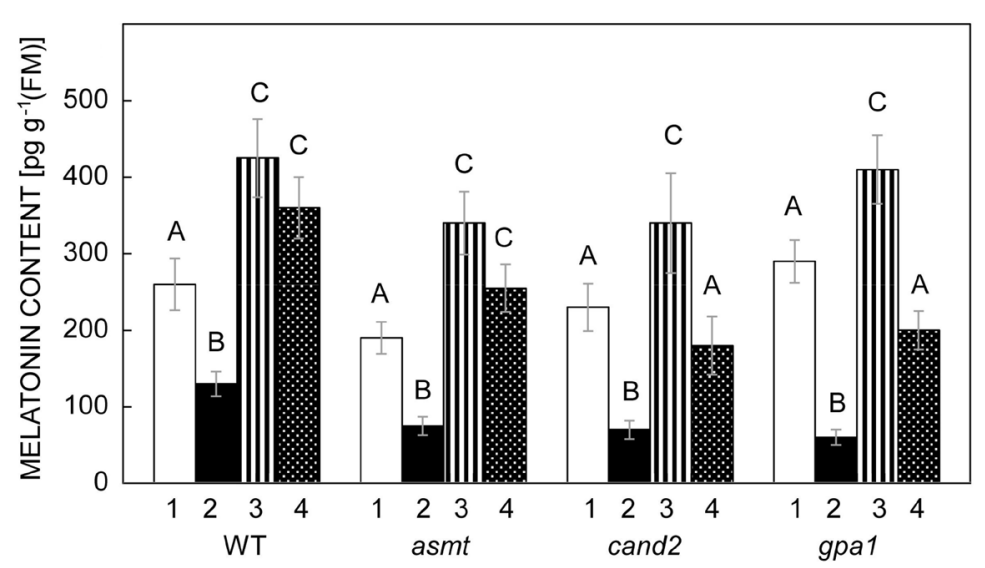

Fig. 1. Melatonin accumulation in Arabidopsis wild plants and mutants for melatonin synthesis and signaling in response to HL stress. 1 - moderate light MS; 2 - HL stress MS; 3 - moderate light MS + melatonin; 4 - HL stress MS + melatonin. Twoweek-old plants were shifted for $72 \mathrm{~h}$ to paper filters moistened with a liquid MS medium supplemented or not with $50 \mu \mathrm{M}$ of melatonin and exposed to HL stress (PPFD of $600 \mu \mathrm{mol} \mathrm{m}^{-2} \mathrm{~s}^{-1}$ ) for $24 \mathrm{~h}$. Control plants were grown under moderate light (PPFD of $60 \mu \mathrm{mol} \mathrm{m}^{-2} \mathrm{~s}^{-1}$ ). The data presented in the figure are the mean values $(n \geq 3)$. Error bars represent SEs. Different letters denote statistically significant differences at $p<0.05$ (ANOVA with post hoc Tukey's multiple-comparison test). 
initial values. In the asmt mutant, HL inhibited the expression of the SNAT1 to a lesser extent and did not affect the level of COMT transcripts. In the cand2 and gpal mutants, stress decreased gene expression to a lesser extent (SNAT1,COMT) as compared to the wild type or did not significantly change it (ASMT).

The transcript levels of the putative participants of melatonin-signaling chain CAND2 and GPA1 were significantly downregulated in the wild type plants and asmt under HL conditions and turned to initial levels $(C A N D 2)$ or were upregulated (GPA1) following HL + melatonin treatment (Fig. 2). However, the cand2 mutant, in which the levels of CAND2 mRNA were comparable to those in the wild type under HL stress, displayed no significant changes of CAND2 mRNA following $\mathrm{HL}+$ melatonin treatment. In parallel, gpal mutant did not show changes of CAND2 mRNA at all, and stress and melatonin-mediated changes of the expression levels of GPA1 were absent in the cand2.

We can conclude that long-term HL oxidative stress was accompanied by activation of the components of the scavenging system and a drop in endogenous melatonin contents. Melatonin treatment under HL contributed to maintaining higher levels of expression of genes for

Table 1. Effect of HL stress and melatonin treatment on the expression of the genes for melatonin synthesis. Two-week-old plants were shifted for $72 \mathrm{~h}$ to paper filters moistened with a liquid MS medium supplemented or not with $50 \mu \mathrm{M}$ of melatonin and exposed to HL stress (PPFD of $600 \mu \mathrm{mol} \mathrm{m}^{-2} \mathrm{~s}^{-1}$ ) for $24 \mathrm{~h}$. Control plants were grown under moderate light (PPFD of $60 \mu \mathrm{mol} \mathrm{m}^{-2} \mathrm{~s}^{-1}$ ). RNAs were analyzed by RT-qPCR using $U B Q 10$ as internal standard. The data presented in the table are the mean values $\pm \mathrm{SE}(n \geq 3)$. Different letters denote statistically significant differences at $p<0.05$ (ANOVA with post hoc Tukey's multiple-comparison test).

\begin{tabular}{lllll}
\hline Genotype & $\begin{array}{l}\text { Moderate light } \\
\text { MS }\end{array}$ & $\begin{array}{l}\text { High light stress } \\
\text { MS }\end{array}$ & $\begin{array}{l}\text { Moderate light } \\
\text { MS + melatonin }\end{array}$ & $\begin{array}{l}\text { High light stress } \\
\text { MS + melatonin }\end{array}$ \\
\hline SNAT & & & & \\
Wild type & $1.000 \pm 0.121^{\mathrm{a}}$ & $0.081 \pm 0.008^{\mathrm{b}}$ & $0.678 \pm 0.098^{\mathrm{c}}$ & $0.480 \pm 0.059^{\mathrm{c}}$ \\
asmt & $1.000 \pm 0.099^{\mathrm{a}}$ & $0.182 \pm 0.020^{\mathrm{b}}$ & $1.097 \pm 0.113^{\mathrm{a}}$ & $0.310 \pm 0.033^{\mathrm{c}}$ \\
cand2 & $1.000 \pm 0.105^{\mathrm{a}}$ & $0.336 \pm 0.051^{\mathrm{b}}$ & $0.962 \pm 0.063^{\mathrm{a}}$ & $0.457 \pm 0.050^{\mathrm{b}}$ \\
gpal & $1.000 \pm 0.102^{\mathrm{a}}$ & $0.678 \pm 0.079^{\mathrm{b}}$ & $0.990 \pm 0.081^{\mathrm{a}}$ & $0.705 \pm 0.045^{\mathrm{b}}$ \\
ASMT & & & & \\
Wild type & $1.000 \pm 0.089^{\mathrm{a}}$ & $0.269 \pm 0.031^{\mathrm{b}}$ & $0.697 \pm 0.057^{\mathrm{c}}$ & $0.577 \pm 0.061^{\mathrm{c}}$ \\
asmt & - & - & - & - \\
cand2 & $1.000 \pm 0.106^{\mathrm{a}}$ & $0.794 \pm 0.086^{\mathrm{a}}$ & $1.154 \pm 0.111^{\mathrm{a}}$ & $1.063 \pm 0.106^{\mathrm{a}}$ \\
gpa1 & $1.000 \pm 0.100^{\mathrm{a}}$ & $0.890 \pm 0.081^{\mathrm{a}}$ & $0.974 \pm 0.084^{\mathrm{a}}$ & $0.735 \pm 0.055^{\mathrm{a}}$ \\
COMT & & & & \\
Wild type & $1.000 \pm 0.121^{\mathrm{a}}$ & $0.193 \pm 0.020^{\mathrm{b}}$ & $0.799 \pm 0.071^{\mathrm{a}}$ & $0.791 \pm 0.069^{\mathrm{a}}$ \\
asmt & $1.000 \pm 0.102^{\mathrm{a}}$ & $0.986 \pm 0.082^{\mathrm{a}}$ & $1.324 \pm 0.121^{\mathrm{a}}$ & $1.136 \pm 0.089^{\mathrm{a}}$ \\
cand2 & $1.000 \pm 0.106^{\mathrm{a}}$ & $0.639 \pm 0.065^{\mathrm{bc}}$ & $0.855 \pm 0.069^{\mathrm{ac}}$ & $0.543 \pm 0.066^{\mathrm{b}}$ \\
gpal & $1.000 \pm 0.092^{\mathrm{a}}$ & $0.675 \pm 0.074^{\mathrm{b}}$ & $0.950 \pm 0.090^{\mathrm{a}}$ & $0.673 \pm 0.045^{\mathrm{b}}$ \\
\hline
\end{tabular}

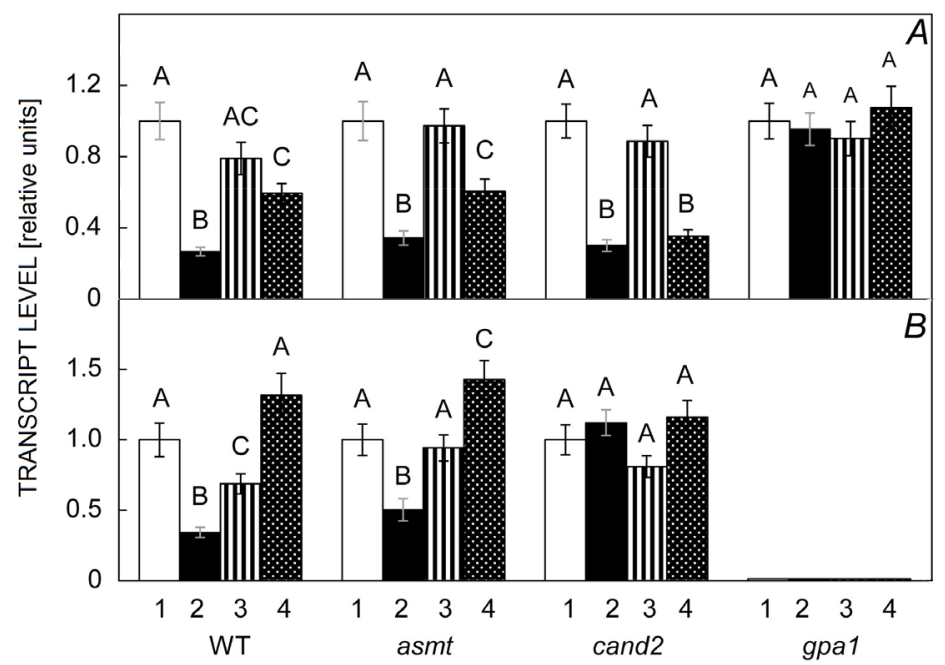

Fig. 2. Effect of HL stress and melatonin treatment on the expression of melatonin-signaling genes: A - CAND2; B - GPA1. 1 - moderate light MS; 2 - HL stress MS; 3 - moderate light MS + melatonin; 4 - HL stress MS + melatonin. Two-week-old plants were shifted for $72 \mathrm{~h}$ to paper filters moistened with a liquid MS medium supplemented or not with $50 \mu \mathrm{M}$ of melatonin and exposed to HL stress (PPFD of $600 \mu \mathrm{mol} \mathrm{m} \mathrm{m}^{-2} \mathrm{~s}^{-1}$ ) for $24 \mathrm{~h}$. Control plants were grown under moderate light (PPFD of $60 \mu \mathrm{mol} \mathrm{m}{ }^{-2}$ $\left.\mathrm{s}^{-1}\right)$. RNAs were analyzed by RT-qPCR using UBQ10 as internal standard. The data presented in the figure are the mean values $(n \geq 3)$. Error bars represent SEs. Different letters denote statistically significant differences at $p<0.05$ (ANOVA with post hoc Tukey's multiple-comparison test). 
melatonin synthesis and signaling in WT and asmt but practically did not affect the expression of these genes in cand2 and gpal.

Photosynthetic activity and expression of chloroplast genes: The plants exposed to HL stress, along with oxidative stress, exhibited a moderate drop in the total Chl content (Table 2), the steady-state levels of which were approximately the same in all genotypes. In wild type and asmt mutant exposed to $\mathrm{HL}$, exogenous melatonin maintained the $\mathrm{Chl}$ amount at a higher level as compared to untreated samples but had no effect in signaling mutants cand 2 and gpal. Similar results were revealed for the total carotenoid content; however, the gpal mutant was not susceptible to its decrease under HL.

The protective effect of melatonin was also shown for the functional activity of the reaction centers of PSII. HL treatment triggered a strong reduction of the maximum quantum yield $\left(\mathrm{F}_{\mathrm{v}} / \mathrm{F}_{\mathrm{m}}\right)$ and effective quantum yield of
PSII $\left(\Phi_{\text {PSII }}\right)$ while melatonin treatment mitigated photoinhibition. The exceptions were cand 2 and gpal. Light stress also increased the nonphotochemical quenching (NPQ) but this response was almost independent of melatonin in all the genotypes studied.

Next, we analyzed whether melatonin affects the expression of chloroplast genes under photooxidative stress. HL exposure increased the level of ELIP1 (EARLY LIGHT-INDUCIBLE PROTEIN 1) transcripts 20-fold in the wild type and more than 40-50-fold in mutants (Table 3). ELIP1 is often used as an indicator of light stress and encodes proteins with photoprotective functions which are directly involved in the synthesis and assembly of specific photosynthetic complexes. Melatonin treatment reduced the expression of ELIP1 by about 1.5 - and 2-fold in the wild type and asmt, respectively, under HL but did not have a reliable effect in the cand 2 and gpal.

In all lines, HL caused a decrease in the transcript accumulation of the nuclear-encoded LHCB2 (light-

Table 2. Effect of HL stress and melatonin treatment on photosynthetic pigment content and chlorophyll fluorescence parameters. Two-week-old plants were shifted for $72 \mathrm{~h}$ to paper filters moistened with a liquid MS medium supplemented or not with $50 \mu \mathrm{M}$ of melatonin and exposed to HL stress (PPFD of $600 \mu \mathrm{mol} \mathrm{m}^{-2} \mathrm{~s}^{-1}$ ) for $24 \mathrm{~h}$. Control plants were grown under moderate light (PPFD of $60 \mu \mathrm{mol} \mathrm{m} \mathrm{m}^{-2} \mathrm{~s}^{-1}$ ). Pigment measurements were performed according to Lichtenthaler (1987). The parameters of activity of PSII were obtained using PAM fluorimetry. The data presented in the table are the mean values $\pm \mathrm{SE}(n \geq 3)$. Different letters denote statistically significant differences at $p<0.05$ (ANOVA with post hoc Tukey's multiple-comparison test).

\begin{tabular}{|c|c|c|c|c|}
\hline Genotype & $\begin{array}{l}\text { Moderate light } \\
\text { MS }\end{array}$ & $\begin{array}{l}\text { High light stress } \\
\text { MS }\end{array}$ & $\begin{array}{l}\text { Moderate light } \\
\text { MS + melatonin }\end{array}$ & $\begin{array}{l}\text { High light stress } \\
\text { MS + melatonin }\end{array}$ \\
\hline \multicolumn{5}{|c|}{ Chlorophyll $(a+b)$ content $\left[\mathrm{mg} \mathrm{g}^{-1}(\mathrm{FM})\right]$} \\
\hline Wild type & $0.946 \pm 0.041^{\mathrm{a}}$ & $0.636 \pm 0.030^{\mathrm{b}}$ & $0.857 \pm 0.065^{\mathrm{a}}$ & $0.745 \pm 0.024^{c}$ \\
\hline asmt & $0.838 \pm 0.040^{\mathrm{a}}$ & $0.537 \pm 0.027^{\mathrm{b}}$ & $0.835 \pm 0.042^{\mathrm{a}}$ & $0.699 \pm 0.031^{\mathrm{c}}$ \\
\hline cand 2 & $0.935 \pm 0.042^{\mathrm{a}}$ & $0.510 \pm 0.031^{\mathrm{b}}$ & $0.836 \pm 0.056^{\mathrm{a}}$ & $0.452 \pm 0.039^{\mathrm{b}}$ \\
\hline gpal & $0.898 \pm 0.039^{\mathrm{a}}$ & $0.650 \pm 0.034^{\mathrm{b}}$ & $0.881 \pm 0.050^{\mathrm{a}}$ & $0.704 \pm 0.037^{\mathrm{b}}$ \\
\hline \multicolumn{5}{|c|}{ Carotenoid content $\left[\mathrm{mg} \mathrm{g}^{-1}(\mathrm{FM})\right]$} \\
\hline Wild type & $0.160 \pm 0.008^{\mathrm{a}}$ & $0.135 \pm 0.009^{\mathrm{b}}$ & $0.154 \pm 0.010^{\mathrm{a}}$ & $0.148 \pm 0.004^{\mathrm{a}}$ \\
\hline asmt & $0.157 \pm 0.004^{\mathrm{a}}$ & $0.139 \pm 0.007^{\mathrm{b}}$ & $0.159 \pm 0.008^{\mathrm{a}}$ & $0.160 \pm 0.006^{\mathrm{a}}$ \\
\hline cand2 & $0.176 \pm 0.012^{\mathrm{a}}$ & $0.109 \pm 0.005^{\mathrm{b}}$ & $0.162 \pm 0.007^{\mathrm{a}}$ & $0.104 \pm 0.005^{\mathrm{b}}$ \\
\hline gpal & $0.151 \pm 0.008^{\mathrm{a}}$ & $0.136 \pm 0.007^{\mathrm{a}}$ & $0.145 \pm 0.008^{\mathrm{a}}$ & $0.146 \pm 0.010^{\mathrm{a}}$ \\
\hline \multicolumn{5}{|l|}{$\mathrm{F}_{\mathrm{v}} / \mathrm{F}_{\mathrm{m}}$} \\
\hline Wild type & $0.816 \pm 0.014^{\mathrm{a}}$ & $0.456 \pm 0.016^{\mathrm{b}}$ & $0.791 \pm 0.013^{\mathrm{a}}$ & $0.564 \pm 0.018^{c}$ \\
\hline asmt & $0.785 \pm 0.006^{\mathrm{a}}$ & $0.402 \pm 0.011^{\mathrm{b}}$ & $0.779 \pm 0.014^{\mathrm{a}}$ & $0.615 \pm 0.023^{\mathrm{c}}$ \\
\hline cand2 & $0.792 \pm 0.020^{\mathrm{a}}$ & $0.469 \pm 0.016^{\mathrm{b}}$ & $0.766 \pm 0.015^{\mathrm{a}}$ & $0.504 \pm 0.026^{\mathrm{b}}$ \\
\hline gpal & $0.812 \pm 0.013^{\mathrm{a}}$ & $0.467 \pm 0.019^{\mathrm{b}}$ & $0.802 \pm 0.006$ & $0.437 \pm 0.020^{\mathrm{b}}$ \\
\hline \multicolumn{5}{|l|}{$\Phi_{\mathrm{PSII}}$} \\
\hline Wild type & $0.661 \pm 0.016^{\mathrm{a}}$ & $0.319 \pm 0.019^{b}$ & $0.646 \pm 0.018^{\mathrm{a}}$ & $0.385 \pm 0.008^{c}$ \\
\hline asmt & $0.644 \pm 0.011^{\mathrm{a}}$ & $0.294 \pm 0.014^{b}$ & $0.630 \pm 0.017^{\mathrm{a}}$ & $0.418 \pm 0.015^{\mathrm{c}}$ \\
\hline cand2 & $0.646 \pm 0.018^{\mathrm{a}}$ & $0.407 \pm 0.021^{\mathrm{b}}$ & $0.621 \pm 0.025^{\mathrm{a}}$ & $0.431 \pm 0.021^{\mathrm{b}}$ \\
\hline gpal & $0.673 \pm 0.012^{\mathrm{a}}$ & $0.357 \pm 0.017^{\mathrm{b}}$ & $0.658 \pm 0.016^{\mathrm{a}}$ & $0.319 \pm 0.036^{\mathrm{b}}$ \\
\hline \multicolumn{5}{|l|}{ NPQ } \\
\hline Wild type & $0.208 \pm 0.013^{\mathrm{a}}$ & $0.306 \pm 0.012^{b}$ & $0.211 \pm 0.013^{\mathrm{a}}$ & $0.267 \pm 0.011^{\mathrm{c}}$ \\
\hline asmt & $0.199 \pm 0.006^{\mathrm{a}}$ & $0.259 \pm 0.008^{b}$ & $0.194 \pm 0.007^{\mathrm{a}}$ & $0.252 \pm 0.015^{\mathrm{b}}$ \\
\hline cand2 & $0.233 \pm 0.018^{\mathrm{a}}$ & $0.299 \pm 0.012^{b}$ & $0.247 \pm 0.005^{\mathrm{a}}$ & $0.285 \pm 0.021^{\mathrm{b}}$ \\
\hline gpal & $0.204 \pm 0.010^{\mathrm{a}}$ & $0.287 \pm 0.011^{\mathrm{b}}$ & $0.235 \pm 0.022^{\mathrm{ac}}$ & $0.277 \pm 0.024^{\mathrm{bc}}$ \\
\hline
\end{tabular}


Table 3. Effect of HL stress and melatonin treatment on the expression chloroplast and nuclear genes. Two-week-old plants were shifted for $72 \mathrm{~h}$ to paper filters moistened with a liquid MS medium supplemented or not with $50 \mu \mathrm{M}$ of melatonin and exposed to HL stress (PPFD of $600 \mu \mathrm{mol} \mathrm{m}^{-2} \mathrm{~s}^{-1}$ ) for $24 \mathrm{~h}$. Control plants were grown under moderate light (PPFD of $60 \mu \mathrm{mol} \mathrm{m}^{-2} \mathrm{~s}^{-1}$ ). RNAs were analyzed by RT-qPCR using $U B Q 10$ as internal standard. The data presented in the table are the mean values $\pm \operatorname{SE}(n \geq 3)$. Different letters denote statistically significant differences at $p<0.05$ (ANOVA with post hoc Tukey's multiple-comparison test).

\begin{tabular}{lllll}
\hline Genotype & $\begin{array}{l}\text { Moderate light } \\
\text { MS }\end{array}$ & $\begin{array}{l}\text { High light stress } \\
\text { MS }\end{array}$ & $\begin{array}{l}\text { Moderate light } \\
\text { MS + melatonin }\end{array}$ & $\begin{array}{l}\text { High light stress } \\
\text { MS + melatonin }\end{array}$ \\
\hline ELIP1 & & & \\
Wild type & $1.000 \pm 0.101^{\mathrm{a}}$ & $23.546 \pm 2.999^{\mathrm{b}}$ & $0.798 \pm 0.088^{\mathrm{a}}$ & $13.802 \pm 1.560^{\mathrm{c}}$ \\
asmt & $1.000 \pm 0.111^{\mathrm{a}}$ & $58.340 \pm 6.291^{\mathrm{b}}$ & $1.654 \pm 0.356^{\mathrm{a}}$ & $30.472 \pm 3.510^{\mathrm{c}}$ \\
cand2 & $1.000 \pm 0.103^{\mathrm{a}}$ & $62.257 \pm 7.998^{\mathrm{b}}$ & $1.226 \pm 0.111^{\mathrm{a}}$ & $49.206 \pm 5.213^{\mathrm{b}}$ \\
gpal & $1.000 \pm 0.108^{\mathrm{a}}$ & $39.279 \pm 4.409^{\mathrm{b}}$ & $0.945 \pm 0.106^{\mathrm{a}}$ & $33.449 \pm 3.721^{\mathrm{b}}$ \\
LHCB2 & & & & \\
Wild type & $1.000 \pm 0.123^{\mathrm{a}}$ & $0.023 \pm 0.003^{\mathrm{b}}$ & $0.918 \pm 0.100^{\mathrm{a}}$ & $0.087 \pm 0.015^{\mathrm{c}}$ \\
asmt & $1.000 \pm 0.098^{\mathrm{a}}$ & $0.015 \pm 0.002^{\mathrm{b}}$ & $1.015 \pm 0.111^{\mathrm{a}}$ & $0.112 \pm 0.016^{\mathrm{c}}$ \\
cand2 & $1.000 \pm 0.101^{\mathrm{a}}$ & $0.044 \pm 0.005^{\mathrm{b}}$ & $0.920 \pm 0.060^{\mathrm{a}}$ & $0.048 \pm 0.060^{\mathrm{b}}$ \\
gpa1 & $1.000 \pm 0.112^{\mathrm{a}}$ & $0.029 \pm 0.030^{\mathrm{b}}$ & $1.114 \pm 0.097^{\mathrm{a}}$ & $0.021 \pm 0.040^{\mathrm{b}}$ \\
psbD & & & & \\
Wild type & $1.000 \pm 0.117^{\mathrm{a}}$ & $0.395 \pm 0.039^{\mathrm{b}}$ & $0.955 \pm 0.119^{\mathrm{a}}$ & $0.706 \pm 0.086^{\mathrm{c}}$ \\
asmt & $1.000 \pm 0.113^{\mathrm{a}}$ & $0.233 \pm 0.039^{\mathrm{b}}$ & $0.898 \pm 0.099^{\mathrm{a}}$ & $0.538 \pm 0.061^{\mathrm{c}}$ \\
cand2 & $1.000 \pm 0.103^{\mathrm{a}}$ & $0.481 \pm 0.044^{\mathrm{b}}$ & $0.905 \pm 0.093^{\mathrm{a}}$ & $0.521 \pm 0.057^{\mathrm{a}}$ \\
gpa1 & $1.000 \pm 0.113^{\mathrm{a}}$ & $0.564 \pm 0.060^{\mathrm{b}}$ & $1.122 \pm 0.121^{\mathrm{a}}$ & $0.517 \pm 0.052^{\mathrm{a}}$ \\
trnE & & & & \\
Wild type & $1.000 \pm 0.102^{\mathrm{a}}$ & $0.494 \pm 0.045^{\mathrm{b}}$ & $0.974 \pm 0.098^{\mathrm{a}}$ & $0.508 \pm 0.056^{\mathrm{b}}$ \\
asmt & $1.000 \pm 0.103^{\mathrm{a}}$ & $0.531 \pm 0.051^{\mathrm{b}}$ & $1.320 \pm 0.129^{\mathrm{a}}$ & $0.554 \pm 0.054^{\mathrm{b}}$ \\
cand2 & $1.000 \pm 0.101^{\mathrm{a}}$ & $0.516 \pm 0.049^{\mathrm{b}}$ & $1.189 \pm 0.109^{\mathrm{a}}$ & $0.612 \pm 0.066^{\mathrm{b}}$ \\
gpa1 & $1.000 \pm 0.099^{\mathrm{a}}$ & $0.683 \pm 0.071^{\mathrm{b}}$ & $1.042 \pm 0.111^{\mathrm{a}}$ & $0.657 \pm 0.069^{\mathrm{b}}$ \\
\hline & & & &
\end{tabular}

harvesting antenna protein of PSII), and a set of selected chloroplast-encoded genes transcribed by PEP ( $r b c L$, $p s b A, p s b D, p s a A, \operatorname{trn} E)$, NEP ( $a c c D)$, or both polymerases $(a t p B)$ (Table 3; Table 3S, supplement). LHCB2 transcript accumulation decreased very significantly and was the most vulnerable to photodamage. The expression of the genes for structural proteins of PSI ( $p s a A)$, PSII ( $p s b A$, $p s b D)$, ATP synthase $(a t p B)$, and acetyl-CoA carboxylase subunit $(a c c D)$ engaged in the fatty acid cycle was downregulated 3-5-fold. It should be noted that the steady-state levels of the above-mentioned gene transcripts were practically the same for all genotypes and did not change when treated with melatonin under moderate light. Melatonin maintained the expression of these genes at a higher level in the stressed wild type, and especially in the asmt mutant, as compared to untreated plants, but had almost no effect in cand 2 and gpal. The only exception was $\operatorname{trn} E$ whose expression was not regulated by melatonin under stress.

Thus, HL significantly suppressed the photosynthetic parameters and the expression of the selected chloroplast genes, while melatonin treatment alleviated this effect. However, mutants for melatonin signaling were compromised for melatonin protective function under photooxidative stress.
The expression of chloroplast RNA polymerase genes: Adjustment of chloroplast gene expression can occur through the regulation of the transcription machinery of chloroplasts. In our experiment, HL stress and exogenous melatonin affected the gene expression of both RNA polymerases (Table 4). However, there were some peculiarities in regulation.

The genes for chloroplast-encoded multi-subunit RNA polymerase of the bacterial type were strongly suppressed by HL in the wild type and asmt, and melatonin treatment maintained their transcript levels at almost initial values. In signaling mutants, melatonin had no effect, with stress downregulating rpo expression to a lesser extent.

The expression of the two genes for nuclear-encoded RNA polymerases differed significantly (Table 4). In the wild type plants, the activity of the chloroplast targeted RPOTp was downregulated 2-fold by $\mathrm{HL}$ and recovered by melatonin to the initial levels. In asmt, HL had a similar effect, but melatonin-induced upregulation was higher. In cand 2 and gpa1, RPOTp transcript accumulation did not change under any of these effectors. On the other hand, the expression of RPOTmp targeted into both chloroplasts and mitochondria was strongly upregulated under photooxidative stress, and melatonin even enhanced 
Table 4. Effect of HL stress and melatonin treatment on the expression of chloroplast RNA polymerase genes. Two-week-old plants were shifted for $72 \mathrm{~h}$ to paper filters moistened with a liquid MS medium supplemented or not with $50 \mu \mathrm{M}$ of melatonin and exposed to HL stress (PPFD of $600 \mu \mathrm{mol} \mathrm{m}^{-2} \mathrm{~s}^{-1}$ ) for $24 \mathrm{~h}$. Control plants were grown under moderate light (PPFD of $60 \mu \mathrm{mol} \mathrm{m}^{-2} \mathrm{~s}^{-1}$ ). RNAs were analyzed by RT-qPCR using $U B Q 10$ as internal standard. The data presented in the table are the mean values $\pm \mathrm{SE}(n \geq 3)$. Different letters denote statistically significant differences at $p<0.05$ (ANOVA with post hoc Tukey's multiple-comparison test).

\begin{tabular}{lllll}
\hline Genotype & $\begin{array}{l}\text { Moderate light } \\
\text { MS }\end{array}$ & $\begin{array}{l}\text { High light stress } \\
\text { MS }\end{array}$ & $\begin{array}{l}\text { Moderate light } \\
\text { MS + melatonin }\end{array}$ & $\begin{array}{l}\text { High light stress } \\
\text { MS + melatonin }\end{array}$ \\
\hline rpoA & & & \\
Wild type & $1.000 \pm 0.101^{\mathrm{a}}$ & $0.235 \pm 0.029^{\mathrm{b}}$ & $0.865 \pm 0.094^{\mathrm{ac}}$ & $0.605 \pm 0.056^{\mathrm{c}}$ \\
asmt & $1.000 \pm 0.109^{\mathrm{ac}}$ & $0.176 \pm 0.020^{\mathrm{b}}$ & $1.245 \pm 0.139^{\mathrm{a}}$ & $0.704 \pm 0.072^{\mathrm{c}}$ \\
cand2 & $1.000 \pm 0.099^{\mathrm{a}}$ & $0.386 \pm 0.041^{\mathrm{b}}$ & $0.957 \pm 0.089^{\mathrm{a}}$ & $0.312 \pm 0.035^{\mathrm{b}}$ \\
gpal & $1.000 \pm 0.104^{\mathrm{a}}$ & $0.528 \pm 0.066^{\mathrm{b}}$ & $0.977 \pm 0.098^{\mathrm{a}}$ & $0.478 \pm 0.055^{\mathrm{b}}$ \\
rpoB & & & & \\
Wild type & $1.000 \pm 0.102^{\mathrm{a}}$ & $0.112 \pm 0.028^{\mathrm{b}}$ & $0.821 \pm 0.084^{\mathrm{a}}$ & $1.301 \pm 0.139^{\mathrm{a}}$ \\
asmt & $1.000 \pm 0.113^{\mathrm{a}}$ & $0.433 \pm 0.047^{\mathrm{b}}$ & $1.086 \pm 0.107^{\mathrm{a}}$ & $0.917 \pm 0.095^{\mathrm{a}}$ \\
cand2 & $1.000 \pm 0.107^{\mathrm{a}}$ & $0.589 \pm 0.061^{\mathrm{b}}$ & $0.814 \pm 0.088^{\mathrm{a}}$ & $0.509 \pm 0.051^{\mathrm{b}}$ \\
gpal & $1.000 \pm 0.100^{\mathrm{a}}$ & $0.730 \pm 0.064^{\mathrm{bc}}$ & $0.892 \pm 0.091^{\mathrm{ab}}$ & $0.560 \pm 0.057^{\mathrm{c}}$ \\
RPOTp & & & & \\
Wild type & $1.000 \pm 0.086^{\mathrm{a}}$ & $0.583 \pm 0.048^{\mathrm{b}}$ & $0.869 \pm 0.085^{\mathrm{a}}$ & $0.676 \pm 0.069^{\mathrm{ab}}$ \\
asmt & $1.000 \pm 0.067^{\mathrm{a}}$ & $0.556 \pm 0.053^{\mathrm{b}}$ & $1.031 \pm 0.120^{\mathrm{a}}$ & $1.766 \pm 0.208^{\mathrm{c}}$ \\
cand2 & $1.000 \pm 0.093^{\mathrm{a}}$ & $0.879 \pm 0.080^{\mathrm{a}}$ & $0.862 \pm 0.094^{\mathrm{a}}$ & $0.883 \pm 0.106^{\mathrm{a}}$ \\
gpal & $1.000 \pm 0.095^{\mathrm{a}}$ & $1.352 \pm 0.198^{\mathrm{a}}$ & $0.987 \pm 0.091^{\mathrm{a}}$ & $1.079 \pm 0.246^{\mathrm{a}}$ \\
RPOTmp & & & & \\
Wild type & $1.000 \pm 0.089^{\mathrm{a}}$ & $1.464 \pm 0.128^{\mathrm{a}}$ & $0.925 \pm 0.088^{\mathrm{a}}$ & $2.006 \pm 0.179^{\mathrm{b}}$ \\
asmt & $1.000 \pm 0.082^{\mathrm{a}}$ & $2.188 \pm 0.208^{\mathrm{b}}$ & $0.963 \pm 0.097^{\mathrm{a}}$ & $4.346 \pm 0.389^{\mathrm{c}}$ \\
cand2 & $1.000 \pm 0.093^{\mathrm{a}}$ & $1.963 \pm 0.199^{\mathrm{b}}$ & $0.830 \pm 0.081^{\mathrm{a}}$ & $2.004 \pm 0.209^{\mathrm{b}}$ \\
gpa1 & $1.000 \pm 0.118^{\mathrm{a}}$ & $2.972 \pm 0.314^{\mathrm{b}}$ & $0.674 \pm 0.088^{\mathrm{c}}$ & $2.365 \pm 0.286^{\mathrm{b}}$ \\
\hline & & & &
\end{tabular}

this effect, but only in the wild type and the mutant for melatonin synthesis.

These data demonstrate that melatonin altered the expression of genes for chloroplast RNA polymerases, in genotypes sensitive to this regulator. At the same time, there were variations in the response of these genes to HL irradiation.

The contents of photosynthetic proteins: To investigate whether the changes of the mRNA profiles correspond to shifts in protein contents, we used immunodetection analysis. A dramatic rise in the accumulation of the marker protein ELIP1 under HL stress was mitigated by melatonin treatment in the wild type and asmt plants (Fig. 3). However, in cand2 and gpal mutants with impaired melatonin perception, elevated contents of ELIP1 were retained after incubation with melatonin.

The reaction center protein D2, the gene product of $p s b D$, exhibited a severe decline following HL stress in all genotypes and especially in asmt. However, it displayed almost initial values in wild-type plants and asmt mutant treated with melatonin. In contrast, decreased contents of D2 after HL exposure remained unaltered in cand2 and gpal following melatonin treatment. These results indicate that the mitigating capacity was attenuated in the mutants with the impaired melatonin perception and that signaling proteins CAND2 and GPA1 are necessary for mediating the melatonin-dependent light-stress response.

The protein contents of RbcL, AtpB, and PsaB were approximately identical in wild type and mutants under all modes of treatment even though corresponding transcript levels were strongly regulated by $\mathrm{HL}$ and melatonin. The unaltered contents of these proteins suggest that the synthesis of these proteins may not be impaired. In addition, the behavior of mRNA levels and translational activity may differ due to reduced protein degradation, as a potential regulatory mechanism (Krantz et al. 2021).

\section{Discussion}

The primary function of melatonin as a scavenger and a broad-spectrum antioxidant is thought to be receptorindependent (Wei et al. 2018). However, its hormonelike signaling function, which is performed through gene expression regulation, was evolved during the subsequent evolution. At high concentrations, melatonin acts primarily as an antioxidant molecule engaged in defense responses while at low concentrations it performs hormone-like functions, though a survey of the relevant literature does not confirm this unambiguously (Arnao and HernándezRuiz 2015). 
WT

asmt

cand2

PsbD

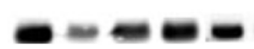

ELIP1

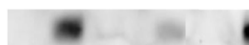

AtpB

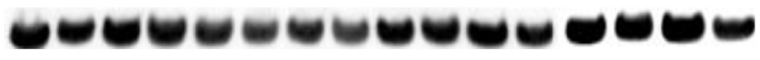

$\mathrm{RbcL}$

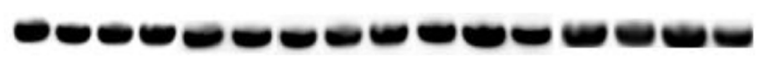

PsaB

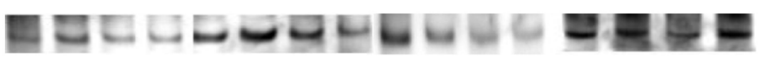

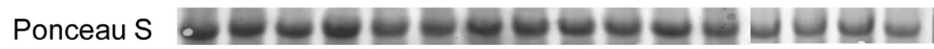

Fig. 3. Western blots of chloroplast-encoded proteins and ELIP1 under HL stress and melatonin treatment. Pouncea S staining was used as a loading control. 1 - moderate light MS; 2 - HL stress MS; 3 - moderate light MS + melatonin; 4 - HL stress $\mathrm{MS}+$ melatonin. Two-week-old plants were shifted for $72 \mathrm{~h}$ to paper filters moistened with a liquid MS medium supplemented or not with $50 \mu \mathrm{M}$ of melatonin and exposed to HL stress (PPFD $600 \mu \mathrm{mol} \mathrm{m}^{-2} \mathrm{~s}^{-1}$ ) for $24 \mathrm{~h}$. Control plants were grown under moderate light (PPFD $60 \mu \mathrm{mol} \mathrm{m} \mathrm{m}^{-2} \mathrm{~s}^{-1}$ ). Proteins were visualized by immunoblotting using antibodies specific for RbcL, PsaB, PsbD, AtpB, and ELIP1 proteins.
A lack of melatonin reduces the vital parameters of plants and reduces resistance to various stressors, as it has been shown in mutants with impaired melatonin biosynthesis genes SNAT, ASMT, COMT (Back 2021). To assess the possible consequences of the shortage of endogenous melatonin under HL stress, we used a single asmt mutant with the disrupted gene for $\mathrm{N}$-acetylserotonin methyltransferase catalyzing the last step of melatonin biosynthesis. Under normal conditions, despite a slight decrease in endogenous melatonin content (Fig. 1), the mutant was indistinguishable from the wild type, probably due to compensatory effects of other biosynthetic enzymes. However, high irradiance caused greater damage in the mutant as could be judged by physiological parameters thereby confirming the beneficial impact of endogenous melatonin. In addition, asmt showed increased sensitivity to exogenous melatonin which was manifested under moderate light and especially under HL stress.

Exogenously applied melatonin increased endogenous concentrations and in addition, activated the expression of genes for melatonin biosynthesis in wild type and asmt. Melatonin is considered to have an amphiphilic nature (Cipolla-Neto and Amaral 2018), which implies a relatively low penetrating ability. Sufficiently strong compartmentalization of the plant cell suggests a complex relationship between an externally penetrating regulator that reduces oxidative stress and a newly synthesized endogenous melatonin targeting regulatory processes. Hence, exogenous melatonin might be a stimulus, which could activate the expression of genes associated with endogenous phytomelatonin biosynthesis and apparently with signaling

The first putative phytomelatonin receptor CAND2/ PMTR1 with a confirmed specific L-melatonin binding was shown to be engaged in signaling transduction cascade regulating stomatal closure in Arabidopsis thaliana (Wei et al. 2018). However, later Lee and Back (2020) showed that CAND2 protein is not functionally associated with melatonin-mediated stress tolerance in response to tunicamycin treatment, which is dependent on MAPK activation. More recently, the role of CAND2/PMTR1 as a potential receptor was corroborated by studies by Wang et al. (2021b) which revealed that CAND2 plays a key role in melatonin-mediated plant response to osmotic stress via modulating the ROS-scavenging ability in Arabidopsis and regulation of $S O D$ and $C A T$ gene expression. In the presented work, we demonstrated that exogenous melatonin can markedly rescue the decreased HL stress tolerance of wild type plants and asmt mutant line, but these effects of melatonin were largely compromised in T-DNA insertion lines cand2/pmtrl and gpal.

It is necessary to mention that gpal and asmt were the bona fide knock-out mutants and exhibited no mRNA expression. At the same time, cand2-1 (Salk_071302), which was used in this study, as well as in the works of Wei et al. (2018) and Wang et al. (2021b), has T-DNA inserted in the promoter region and under moderate light, the expression levels of CAND2 mRNA in the cand2-1 mutant were comparable to those in the wild type. Nonetheless, the mutant was more sensitive to HL stress (Fig. 1) and exhibited decreased melatonin accumulation in conjunction with the enhanced expression of the genes for melatonin biosynthesis. In addition, melatoninmediated changes of the expression levels of CAND2 and GPA1 were abolished in the cand2. This data suggest that T-DNA insert in the promoter may result in impairment of transcription regulation under adverse conditions.

Receptor-dependent effects of melatonin treatment were mainly associated with the changes of photosynthetic activity (pigment content and fluorescence parameters) and the expression of the chloroplast genome. At the same time, the scavenging properties of melatonin, judging from $\mathrm{H}_{2} \mathrm{O}_{2}$ contents and SOD activity, proved to be receptorindependent.

To evaluate the possible outcome of melatonin treatment on the expression of the chloroplast genome, we studied the transcript levels of selected chloroplastencoded genes belonging to different operons and functional complexes and transcribed by various RNA polymerases. Under moderate light, exogenous melatonin did not trigger up- or downregulation of chloroplast gene expression. Interestingly, according to transcriptome data, treatment with melatonin even inhibited the expression of several genes encoding the subunits of PSI and PSII (Wan et al. 2018). However, in our experiments, melatonin was particularly effective in maintaining elevated levels of chloroplast transcripts and the corresponding photosynthetic proteins under HL, as compared with transcript levels of untreated stressed seedlings. Nevertheless, except for $r p o B$ encoding $\beta$-subunit of PEP, none of them exceeded the control values, probably due to severe injury caused by prolonged HL exposition $(24 \mathrm{~h})$. It should 
be emphasized that in contrast to the results of Lee and Back (2018), which showed that melatonin content and the expression of its biosynthesis genes were transiently induced under less prolonged HL stress (3-6h), in our experimental setting, endogenous melatonin concentration decreased, as well as the expression of biosynthesis genes (Fig. 1, Table 1).

The activity of chloroplast genes, at least in part, may be maintained due to the elevated expression of genes for chloroplast RNA polymerases. Previously, we showed that under mild photooxidative stress melatonin induces the expression of genes for almost all elements of the chloroplast transcription machinery, including NEP, PEP, sigma factors, and PEP-associated proteins in detached Arabidopsis leaves (Bychkov et al. 2019). In the described experimental design, melatonin rather maintained the activity of PEP and RPOTp under increased photodamage, although in the highly sensitive asmt mutant, it even induced RPOTp expression in stress conditions. The elevated transcript level of chloroplast RNA polymerases probably provides additional opportunities for better recovery of photosynthetic processes and accelerated adaptation to changing conditions (Table 4).

The putative role of chloroplast RNA polymerases in managing melatonin-dependent upregulation of chloroplast genes is confirmed by the fact that transcript levels of trnE encoding tRNA-Glu did not respond to melatonin treatment. tRNA-Glu, in addition to its well-known fundamental functions in translation and 5-aminolevulinate synthesis, functions as an inhibitor of RPOTp-dependent transcription. Hence, the induction of $\operatorname{trn} E$ under deleterious conditions could result in downregulation of RPOTp gene expression, thereby reducing chloroplast transcription and HL tolerance.

In contrast to RPOT, RPOTmp expression was upregulated by HL stress, and melatonin augmented this reaction in a receptor-dependent manner. Since RPOTmp is active mainly in mitochondria where it modulates the expression of the genes belonging to respiratory complexes I and IV (Kühn et al. 2009, Tarasenko et al. 2016), its induction upon HL and melatonin treatment suggests the role in the melatonin-dependent expression of mitochondrial genes. Indeed, under photooxidative stress generating intensive ROS production, exogenously applied melatonin induced mitochondrial RNA-polymerase gene RPOTm and maintained the expression of mitochondrial encoded genes, operating through the CAND2 and GPA. Unlike wild-type plants, cand 2 and gpal did not show a decrease in the alternative pathway of leaf respiration, as well as the activity of an alternative oxidase, and the expression of the $A O X 1 a$ gene when treated with melatonin under excessive light (Bychkov et al., unpublished results).

Mitochondria are known to be one of the sites of melatonin synthesis (Wang et al. 2017). Moreover, in addition to chloroplasts, mitochondria are hypothesized to be the original sites of melatonin synthesis in the early stage of endosymbiotic organisms (Tan et al. 2013). These data imply that melatonin may act as an essential regulatory element of organelle gene expression. Hence, a challenge for future research is to elucidate the molecular chain linking melatonin to organelle gene expression and possible outcomes for inter-organelle and organelle to nucleus communication.

CAND2 and GPA1 with their predicted localization in chloroplasts and mitochondria (http://bar.utoronto.ca/cell efp/cgi-bin/cell_efp.cgi) may represent the input points of melatonin-mediated signaling pathway which is involved in HL stress responses of plant organelles. However, components and the hierarchical structure of signaling pathways directing melatonin signals to the nucleus, as well as targets of downstream transcription factors affecting organelle genome expression, remain unclear. It might be that WRKY54 whose expression is perturbed in cand 2 and gpal, is involved in melatonin-mediated signaling network associated with defense responses. However, direct interaction between CAND2 and GPA1, on one hand, and WRKY54, on the other, remains to be shown. Transcriptome analysis revealed a total of 29 genes for transcription factors that were upregulated by melatonin treatment (Weeda et al. 2014). These findings, together with the data on phytomelatonin receptors, provide a starting point for unraveling the molecular mechanisms that link melatonin perception and function in various physiological responses.

In conclusion, we have shown for the first time that putative melatonin receptor CAND2/PMTR1 which is associated with G-protein GPA1 is an essential factor for protection under HL stress. Mutants with the impaired function of this signaling circuit were partially insensitive to melatonin treatment upon HL. The higher degree of photodamage could be due to a significantly decreased photosynthetic activity as measured by maximum quantum yield and effective quantum yield of PSII and diminished expression of chloroplast genes, both of nuclear and chloroplast coding. Along with data on the regulation of stomatal closure (Wei et al. 2018) and osmotic stress tolerance in Arabidopsis (Wang et al. 2021b), our results confirmed the participation of CAND2/PMTR1 and GPA1 in melatonin-mediated signaling transduction and their essential role in photosynthesis and related processes under stress conditions which is at least partially due to the control of chloroplast gene expression.

\section{References}

Arnao M.B., Hernández-Ruiz J.: Functions of melatonin in plants: a review. - J. Pineal Res. 59: 133-150, 2015.

Back K.: Melatonin metabolism, signaling and possible roles in plants. - Plant J. 105: 376-391, 2021.

Back K., Tan D.X., Reiter R.J.: Melatonin biosynthesis in plants: multiple pathways catalyze tryptophan to melatonin in the cytoplasm or chloroplasts. - J. Pineal Res. 61: 426-437, 2016.

Bychkov I., Kudryakova N., Andreeva A. et al.: Melatonin modifies the expression of the genes for nuclear- and plastidencoded chloroplast proteins in detached Arabidopsis leaves exposed to photooxidative stress. - Plant Physiol. Bioch. 144: 404-412, 2019.

Cipolla-Neto J., Amaral F.G.: Melatonin as a hormone: New physiological and clinical insights. - Endocr. Rev. 39: 9901028, 2018.

Danilova M.N., Kudryakova N.V., Andreeva A.A. et al.: Differential impact of heat stress on the expression of 
chloroplast-encoded genes. - Plant Physiol. Bioch. 129: 90-100, 2018.

Gruszecki W.I.: Light-driven regulatory mechanisms in the photosynthetic antenna complex LHCII. - Biochem. Soc. T. 38: 702-704, 2010.

Heddad M., Noren H., Reiser V. et al.: Differential expression and localization of early light-induced proteins in Arabidopsis. Plant Physiol. 142: 75-87, 2006.

Kozuleva M.A., Lysenko E.A., Klaus A.A., Kuznetsov V.V.: Long-term hyperthermia impairs activity of both photosystems. - Dokl. Biochem. Biophys. 472: 71-73, 2017.

Krantz M., Legen J., Gao Y. et al.: Modeling indicates degradation of mRNA and protein as a potential regulation mechanisms during cold acclimation. - J. Plant Res. 134: 873-883, 2021.

Kühn K., Richter U., Meyer E.H. et al:: Phage-type RNA polymerase RPOTmp performs gene-specific transcription in mitochondria of Arabidopsis thaliana. - Plant Cell 21: 27622779, 2009.

Kusnetsov V.V.: Chloroplasts: Structure and expression of the plastid genome. - Russ. J. Plant Physiol. 65: 465-476, 2018.

Lee H.Y., Back K.: Melatonin induction and its role in high light stress tolerance in Arabidopsis thaliana. - J. Pineal. Res. 65: e12504, 2018.

Lee H.Y., Back K.: The phytomelatonin receptor (PMRT1) Arabidopsis Cand2 is not a bona fide G protein-coupled melatonin receptor. - Melatonin Res. 3: 177-186, 2020.

Lee H.Y., Back K.: Melatonin regulates chloroplast protein quality control via a mitogen-activated protein kinase signaling pathway. - Antioxidants 10: 511, 2021.

Li D., Wei J., Peng Z. et al.: Daily rhythms of phytomelatonin signaling modulate diurnal stomatal closure via regulating reactive oxygen species dynamics in Arabidopsis. - J. Pineal Res. 68: e12640, 2020.

Lichtenthaler H.K.: Chlorophylls and carotenoids: pigments of photosynthetic biomembranes. - Method. Enzymol. 148: 350382, 1987.

Pfannschmidt T., Blanvillain R., Merendino L. et al.: Plastid RNA polymerases: orchestration of enzymes with different evolutionary origins controls chloroplast biogenesis during the plant life cycle. - J. Exp. Bot. 66: 6957-6973, 2015.

Reiter R.J., Tan D.X., Zhou Z. et al.: Phytomelatonin: assisting plants to survive and thrive. - Molecules 20: 7396-7437, 2015.
Sharif R., Xie C., Zhang H. et al.: Melatonin and its effects on plant systems. - Molecules 23: 2352, 2018.

Sun C., Liu L., Wang L. et al.: Melatonin: A master regulator of plant development and stress responses. - J. Integr. Plant Biol. 63: 126-145, 2021.

Tan D.X., Manchester L.C., Liu X. et al.: Mitochondria and chloroplasts as the original sites of melatonin synthesis: a hypothesis related to melatonin's primary function and evolution in eukaryotes. - J. Pineal Res. 54: 127-138, 2013.

Tarasenko V.I., Katyshev A.I., Yakovleva T.V. et al.: RPOTmp, an Arabidopsis RNA polymerase with dual targeting, plays an important role in mitochondria, but not in chloroplasts. J. Exp. Bot. 67: 5657-5669, 2016.

Wan J., Zhang P., Wang R. et al.: Comparative physiological responses and transcriptome analysis reveal the roles of melatonin and serotonin in regulating growth and metabolism in Arabidopsis. - BMC Plant Biol. 18: 362, 2018.

Wang D.Y, Wang J., Shi S.H. et al.: Exogenous melatonin ameliorates salinity-induced oxidative stress and improves photosynthetic capacity in sweet corn seedlings. Photosynthetica 59: 327-336, 2021a.

Wang L., Feng C., Zheng X. et al.: Plant mitochondria synthesize melatonin and enhance the tolerance of plants to drought stress. - J. Pineal Res. 63: e12429, 2017.

Wang L.F., Li T.T., Zhang Y. et al:: CAND2/PMTR1 is required for melatonin-conferred osmotic stress tolerance in Arabidopsis. - Int. J. Mol. Sci. 22: 4014, 2021 b.

Weeda S., Zhang N., Zhao X. et al.: Arabidopsis transcriptome analysis reveals key roles of melatonin in plant defense systems. - PLoS ONE 9: e93462, 2014.

Wei J., Li D.X., Zhang J.R. et al.: Phytomelatonin receptor PMTR1-mediated signaling regulates stomatal closure in Arabidopsis thaliana. - J. Pineal Res. 65: e12500, 2018.

Zhang M., He S., Zhan Y. et al.: Exogenous melatonin reduces the inhibitory effect of osmotic stress on photosynthesis in soybean. - PLoS ONE 14: e0226542, 2019.

Zhao D., Yu Y., Shen Y. et al.: Melatonin synthesis and function: evolutionary history in animals and plants. - Front. Endocrinol. 10: 249, 2019.

Zhou X., Zhao H., Cao K. et al.: Beneficial roles of melatonin on redox regulation of photosynthetic electron transport and synthesis of D1 protein in tomato seedlings under salt stress. - Front. Plant Sci. 7: 1823, 2016.

(C) The authors. This is an open access article distributed under the terms of the Creative Commons BY-NC-ND Licence. 